\title{
Osteoclast activity modulates B-cell development in the bone marrow
}

Anna Mansour ${ }^{1,2}$, Adrienne Anginot ${ }^{3,4}$, Stéphane J C Mancini ${ }^{3,4}$, Claudine Schiff ${ }^{3,4}$, Georges F Carle ${ }^{1,2}$, Abdelilah Wakkach ${ }^{1,2,5}$, Claudine Blin-Wakkach ${ }^{1,2,5}$

${ }^{1}$ CNRS, GEPITOS, UMR 6235, Faculté de Médecine, 06100 Nice, France; ${ }^{2}$ Université de Nice Sophia Antipolis, 06000 Nice, France; ${ }^{3}$ Centre d'Immunologie de Marseille Luminy; INSERM, CNRS, Parc Scientifique de Luminy, 13288 Marseille cedex 09, France; ${ }^{4}$ Université de la Méditerranée, Parc Scientifique de Luminy, 13288 Marseille cedex 09, France; ${ }^{5}$ INSERM, UMR 576, Hôpital de l'Archet, 06202 Nice, France

B-cell development is dependent on the interactions between B-cell precursors and bone marrow stromal cells, but the role of osteoclasts (OCLs) in this process remains unknown. B lymphocytopenia is a characteristic of osteopetrosis, suggesting a modulation of B lymphopoiesis by OCL activity. To address this question, we first rescued OCL function in osteopetrotic oc/oc mice by dendritic cell transfer, leading to a restoration of both bone phenotype and B-cell development. To further explore the link between OCL activity and B lymphopoiesis, we induced osteopetrosis in normal mice by injections of zoledronic acid (ZA), an inhibitor of bone resorption. B-cell number decreased specifically in the bone marrow of ZA-treated mice. ZA did not directly affect B-cell differentiation, proliferation and apoptosis, but induced a decrease in the expression of CXCL12 and IL-7 by stromal cells, associated with reduced osteoblastic engagement. Equivalent low osteoblastic engagement in oc/oc mice confirmed that it resulted from the reduced OCL activity rather than from a direct effect of $\mathrm{ZA}$ on osteoblasts. These dramatic alterations of the bone microenvironment were disadvantageous for B lymphopoiesis, leading to retention of B-cell progenitors outside of their bone marrow niches in the ZA-induced osteopetrotic model. Altogether, our data revealed that OCLs modulate B-cell development in the bone marrow by controlling the bone microenvironment and the fate of osteoblasts. They provide novel basis for the regulation of the retention of $B$ cells in their niche by OCL activity.

Keywords: osteopetrosis; osteoclast; hematopoietic niche; B cells

Cell Research (2011) 21:1102-1115. doi:10.1038/cr.2011.21; published online 15 February 2011

\section{Introduction}

Interactions between the bone and immune systems are essential for the differentiation of immune cells in the bone marrow and the function of bone cells in health and diseases [1]. In particular, bone provides a microenvironment that is critical for hematopoiesis. Indeed, stromal cells and osteoblasts, which produce bone matrix, function as major support cells for hematopoietic stem cells [2-4] and B lymphocytes [5, 6].

$\mathrm{B}$ lymphopoiesis is a highly ordered process taking

Correspondence: Claudine Blin-Wakkach

Tel: 0033492157 702; Fax: 0033492157709

E-mail: blin@unice.fr

Received 26 April 2010; revised 14 November 2010; accepted 30 November 2010; published online 15 February 2011 place in the bone marrow. Distinct stages in B-cell development have been defined based on the expression of particular surface phenotypic markers [7, 8]. Pre-pro-B cells are the earliest B-cell precursors and develop to pro-B, pre-B and finally immature B cells. Immature B cells emigrate from the bone marrow and mature in the spleen. In the bone marrow, progression of B cells along this process requires physical contact with osteoblasts and stromal cells $[6,9]$, and ablation of these cells results in a defect in B lymphopoiesis [9]. Interaction between stromal cells and B-cell progenitors involves growth factors, chemokines, and their receptors, among which CXCL12 and IL-7 are essential: CXCL12 is necessary for the development of early B-cell precursors and their retention in the bone marrow [10-12] and IL-7 is important for the progression to pre-B cells [13]. Furthermore, analysis of the B-cell niches in the bone marrow 
has revealed that early B-cell precursors progress from niches formed by $\mathrm{CXCL} 12^{+}$stromal cells, to that of IL- $7^{+}$ stromal cells, and become independent of $\mathrm{IL}^{-} 7^{+}$cells at the pre-B stage [5]. These data reveal a fine spatial organization of the B-cell niches in the bone marrow. Therefore, it is likely that alterations in the bone marrow microenvironment affect $\mathrm{B}$ lymphopoiesis.

Bone homeostasis results from a fine balance between the activity of osteoblasts and the activity of osteoclasts (OCLs), which are responsible for bone resorption. Osteopetrosis is characterized by an absence of bone resorption leading to an increased bone mass and severe alteration in the bone microenvironment. In mice, gene mutations leading to osteopetrosis have been associated with reduced B-cell development [14-20]. However, in these models, it is not clear whether the low B-cell number is because of the mutation itself, or is a consequence of microenvironmental modifications resulting from the absence of OCL activity.

Among these mutant models, we have shown that B lymphopoiesis is altered in osteopetrotic oc/oc mice that show a spontaneous mutation in the Tcirgl gene encoding the a3 subunit of the V-ATPase necessary for bone resorption $[20,21]$. These mice are characterized by fully differentiated but inactive OCLs and have an extremely severe and lethal osteopetrotic phenotype. In these mice, transition between pro- and pre-B cells is dramatically reduced because of the decrease in IL-7 expression in the bone marrow, leading to the accumulation of an atypical pro-B-cell population [20, 22]. Injection of IL-7 partly restores $B$ lymphopoiesis, suggesting that the defect in B-cell differentiation in these mice probably results from microenvironmental modifications [23]. However, analysis in this model is limited because of the low cellularity of the bone marrow and the short life span of the oc/oc mice [20]. Therefore, the use of inducible models of mild osteopetrosis may represent an appropriate approach to study the link between OCL activity and B-cell development.

Zoledronic acid (ZA) is a nitrogen-containing bisphosphonate that potently inhibits OCL activity [24]. ZA binds to mineralized bone matrix, is uptaken by OCLs during bone resorption and inhibits enzymatic pathways, resulting in decreased OCL activity and inhibition of bone resorption [24]. In rodents, long-term treatment with ZA induces a mild osteopetrotic-like phenotype [25, 26]. Regarding the B-cell lineage, ZA has an antitumor potential against myeloma plasma cells by inducing their apoptosis and interfering with the stromal cells necessary for their niche, but no data have been reported regarding ZA effect on B-cell precursors [27, 28].

The aim of this study was to better understand the link between OCL activity and B lymphopoiesis. In osteopetrotic $o c / o c$ mice, we restored OCL activity by transfer of dendritic cells (DCs) from normal mice as described recently [29]. We showed that this specific rescue of bone resorption is sufficient to increase B lymphopoiesis, confirming the importance of OCL activity in modulating the environment necessary for B-cell development in the bone marrow. To further analyze the mechanisms involved in this process, we induced mild osteopetrosis in normal mice with repeated injections of ZA according to a previously published protocol [26]. We showed that this treatment specifically affected B-cell development in the bone marrow, not directly but through microenvironmental modifications, including decreased osteoblastic engagement because of the strong reduction of OCL activity. As a consequence, B-cell progenitors were less retained in the bone marrow and homed in other organs such as the spleen. This work clearly establishes a role of OCL activity in the control of B-cell development in the bone marrow through the modulation of the mesenchymal cells forming the B-cell niches.

\section{Results}

Restoration of bone resorption in oc/oc mice rescues $B$ lymphopoiesis

In osteopetrotic oc/oc mice, B lymphopoiesis is blocked at the stage of pro-B to pre-B-cell transition [20]. To clearly establish the link between this block and absence of OCL activity, we have restored bone resorption in these mice. Several studies reported a restoration of OCL function and hematopoiesis using transfer of hematopoietic cells into newborn oc/oc mice [30, 31], but they did not allow to conclude on the effect of OCL function on B lymphopoiesis because the transferred cells contained cells from the B lineage.

Recently, we have reported that transfer of splenic conventional DCs (cDCs), after depletion of cells from the $\mathrm{B}$ lineage, restored OCL activity in $o c / o c$ mice through the differentiation of cDCs into functional OCLs [29]. We have previously reported that this approach allowed one to rescue the osteopetrotic phenotype of the mice as assessed by (i) the presence of a bone marrow cavity in long bones which is absent in untreated $o c / o c$ mice, (ii) an increased life span which is under 3 weeks in untreated $o c / o c$ mice, (iii) an increased bone marrow cellularity and (iv) the modification of histomorphometric parameters indicating a restoration of the bone turnover [29]. In these mice, we have analyzed the major B-cell populations present in the bone marrow (Figure 1), at day 18 for $o c / o c$ mice (because of their short life span) and at day 50 for $+/+$ and DC-treated oc/oc mice 

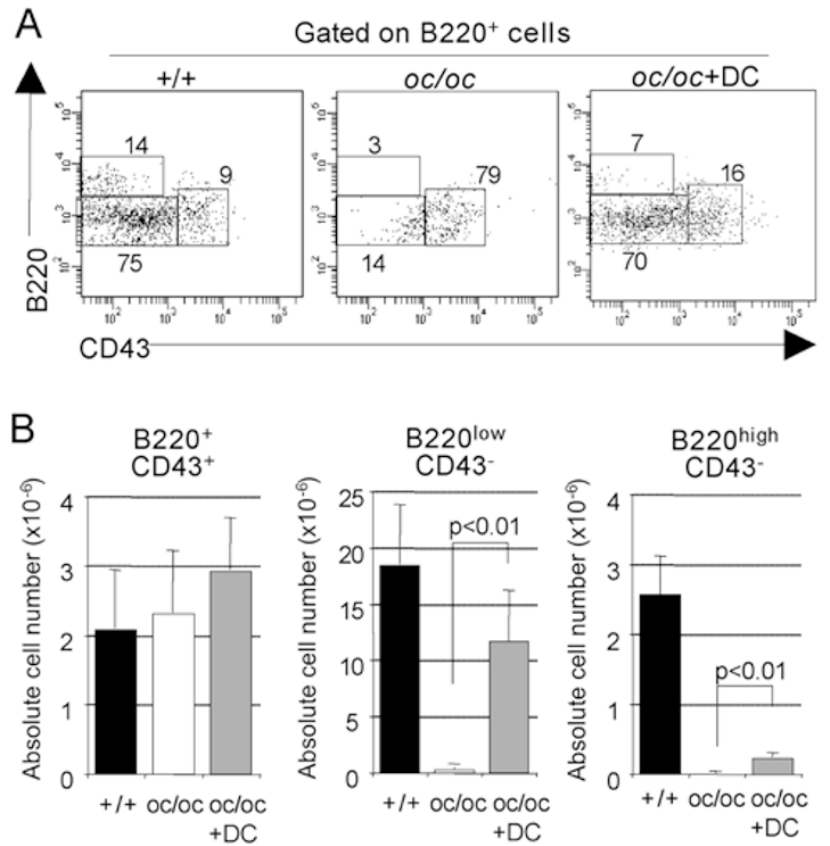

Figure 1 Restoration of osteoclast activity in osteopetrotic oc/oc mice results in a rescue of $B$ lymphopoiesis. (A) B-cell subsets were analyzed by flow cytometry on $\mathrm{B}_{2} 2 \mathrm{O}^{+}$cells from the bone marrow of $+/+$ mice, control oc/oc mice and DC-treated oc/oc mice $(o c / o c+D C)$. They were defined as follows: pro-B cells =

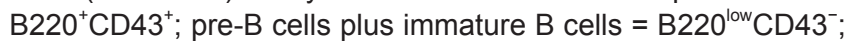
recirculating $B$ cells $=B 220^{\text {high }} \mathrm{CD}_{4} 3^{-}$. Percentage of each subset is indicated. The figure is representative of the results obtained for three mice in each group. (B) Absolute cell number of each subset was calculated from the flow cytometric analysis and is presented as the mean \pm SD of three mice per group $(P$ $<0.01)$.

(because of the time necessary to reach restoration of the bone turnover [29]). In control oc/oc mice, the percentage of $\mathrm{B} 220^{+} \mathrm{CD} 43^{+}$pro-B cells increased, and that of $\mathrm{B} 220^{+} \mathrm{CD} 43^{-}$pre-B plus immature $\mathrm{B}$ cells decreased compared with $+/+$ mice, as described previously [20]. Very interestingly, in DC-treated oc/oc mice, this block in B lymphopoiesis is rescued, as shown by the high percentage and absolute number of $\mathrm{B} 220^{+} \mathrm{CD} 43^{-}$pre- $\mathrm{B}$ plus immature $\mathrm{B}$ cells compared with control oc/oc mice (Figure 1A and 1B). Thus, rescue of OCL function in osteopetrotic $o c / o c$ mice has led to a restoration of B cell development.

\section{$Z A$ injection induces changes in bone phenotype and bone marrow microenvironment}

The $o c / o c$ mouse is characterized by a dramatically severe phenotype [20] and analysis on this model is very limited. Therefore, to better understand how OCL activity can control B-cell development, we have used an osteopetrotic model induced by ZA injection [26]. Radiographic analysis of long bones from lower limbs of phosphate-buffered saline (PBS)- and ZA-treated mice revealed that $Z A$ induced an increase in the bone density localized to the distal part of the femur and the proximal part of the tibia (Figure 2A) as described previously [26]. This result was confirmed by $\mu \mathrm{Ct}$ analysis (Figure $2 \mathrm{~B}$ and $2 \mathrm{C}$ ). Longitudinal and cross-sectional reconstructions of femora showed a severely increased trabecular zone in ZA-treated mice compared with controls (Figure 2B). Quantification of the morphological indices of the femora demonstrated a $180 \%$ increase in trabecular bone volume per tissue volume (BV/TV) on ZA treatment. This increase resulted from an augmentation in trabecular thickness, number and density as well as a parallel decrease in trabecular spacing (Figure 2C).

Histological analysis of femora confirmed these results: the trabecular region of ZA-treated mice showed large zones of mineralized bone matrix, and was highly disorganized compared with control mice (Figure 2D). In these zones, staining of tartrate-resistant acid phosphatase (TRACP) revealed that a large number of OCLs were not attached to the bone surface in ZA-treated mice compared with controls (Figure 2E). An equivalent phenotype of OCLs has previously been observed in a patient displaying bisphosphonate-induced osteopetrosis [32]. Moreover, we did not find significant difference in the number of OCLs derived in vitro from the bone marrow of PBS- or ZA-treated mice (Figure 2F), and these OCLs are able to resorb dentin slices (Figure 2G), indicating that the number of OCL precursors and their osteoclastogenic potential are not affected by ZA treatment. Lastly, the bone marrow cellularity was decreased about $30 \%$ in ZA-treated mice compared with controls (Figure $2 \mathrm{H})$.

Altogether, these data clearly demonstrated that ZA has induced an osteopetrotic-like phenotype in treated mice, with important modifications in the bone microenvironment, as expected. Moreover, the augmentation in bone density induced by ZA is more probably linked to a decrease in OCL resorbing activity, because of the partial loss of adhesion, rather than to a decrease in OCL number.

\section{B lymphopoiesis is altered in ZA-treated mice}

We then analyzed by flow cytometry the B lymphoid and myeloid populations present in the bone marrow of lower limbs (Figure 3). The percentage of $\mathrm{CD} 19^{+} \mathrm{B} 220^{+}$ total $\mathrm{B}$ cells was reduced in the bone marrow of $\mathrm{ZA}$ treated mice compared with controls, whereas the per-

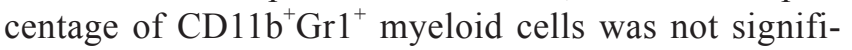



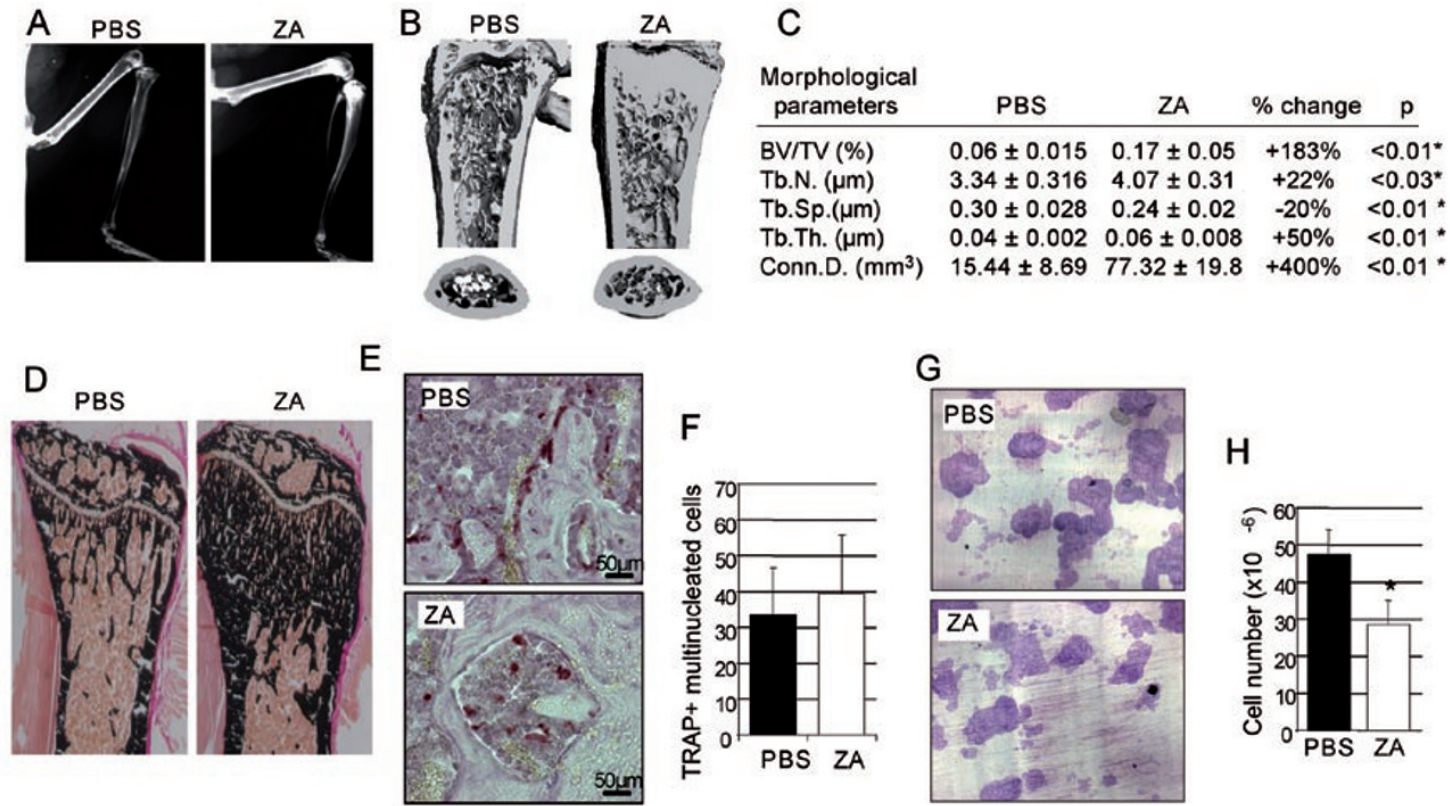

Figure 2 ZA injection induces changes in bone phenotype and bone marrow microenvironment. (A) X-ray analysis of long bones from PBS- and ZA-treated mice. (B) Longitudinal and cross-sectional $\mu C t$ reconstruction of the distal femur of PBSand ZA-treated mice. (C) Morphological analysis by $\mu$ Ct of the femur from PBS- and ZA-treated mice. Trabecular indices were computed from $\mu \mathrm{Ct}$ scans. BV/TV: trabecular bone volume per tissue volume, Tb.N: trabecular number, Tb.Sp: trabecular spacing, Tb.Th: trabecular thickness and Conn.D: connectivity density. The data are presented as the mean \pm SD of 6 mice per group. $P$-was calculated with a Student's $t$-test. (D) Von-Kossa staining and (E) TRACP staining of the femoral bone of PBS- and ZA-treated mice. (F) Enumeration of OCLs (defined as TRACP ${ }^{+}$multinucleated cells) obtained in vitro from bone marrow cells from PBS- and ZA-treated mice. Results are presented as the mean \pm SD of at least six wells for each condition and are representative of two independent experiments. No significant difference was observed. (G) Resorption activity of the in vitro differentiated OCLs. After culture onto dentin slices, OCLs were removed by sonication and resorption lacunae were detected by staining with toluidine blue. $(\mathrm{H})$ Bone marrow cellularity in the long bones (femurs and tibias) of PBS- and ZAtreated mice. Results are presented as the mean \pm SD of 9 to 12 mice per group. ${ }^{*} P<0.05$.

cantly altered in treated mice (Figure 3A).

B-cell subsets are identified by the expression of specific patterns of membrane markers [7, 8]. From the pro-B stage, the percentage and number of all B-cell subsets were decreased in ZA-treated mice (Figure 3B3C). We have also analyzed earlier B-cell progenitors using the recently described marker Ly6D [33], as well as hematopoietic stem cells (HSCs). The percentage and absolute number of pre-pro-B cells were also decreased in the bone marrow of ZA-treated mice compared with controls, whereas common lymphoid progenitors (CLPs) and HSCs were not significantly affected (Figure 3D$3 \mathrm{G})$. Comparison of the mean cell number of each subset between control and ZA-treated mice confirmed that all B cell subsets were decreased by twofold, but this was not the case for CLPs and HSCs (Supplementary information, Figure S1). These results suggest that B-cell development is impaired in the bone marrow of ZA-treated mice, starting from the pre-pro-B stage.

\section{$Z A$ does not affect $B$ cell differentiation, proliferation} and apoptosis

The reduction in B-cell number observed in the bone marrow of ZA-treated mice could be because of the reduced proliferation, an increased apoptosis or a block in their differentiation. In vivo analysis of the proliferation of $\mathrm{CD}_{19^{+}} \mathrm{IgM}^{-} \mathrm{B}$-cell progenitors in the bone marrow after BrdU incorporation did not evidence any significant change between ZA-treated and control mice (Figure 4A). Furthermore, evaluation of apoptosis using annexin-V labeling on $\mathrm{CD} 19^{+} \mathrm{B}$-cell membrane did not reveal any change between control and ZA-treated mice (Figure 4B).

To examine whether ZA could block B-cell differentiation, $\mathrm{CD} 19^{+} \mathrm{B} 220^{\text {low }} \mathrm{IgM}^{-}$B-cell progenitors were sorted from the bone marrow of normal mice, layered onto ST2 stromal cells and cultured in the presence of IL-7 at different concentrations of ZA. In this system, the differentiation of $\mathrm{B} 220^{+} \mathrm{CD} 43^{+}$pro-B cells into $\mathrm{B} 220^{+} \mathrm{CD} 43^{-}$ 


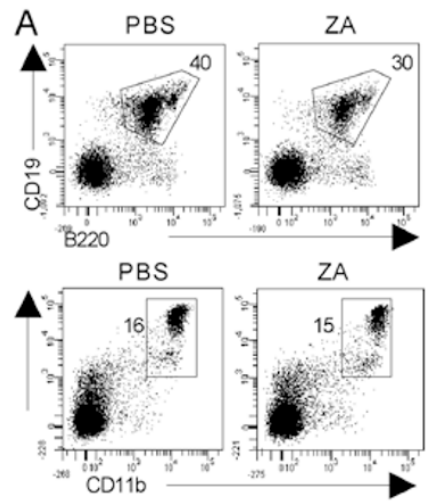

B

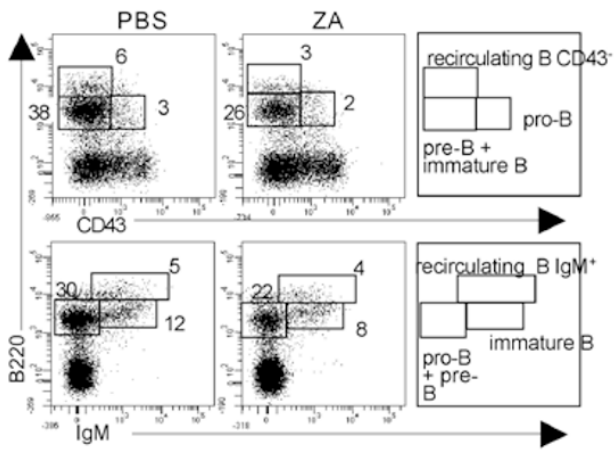

C

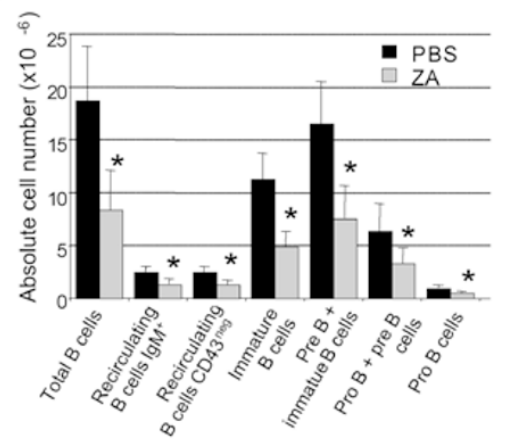

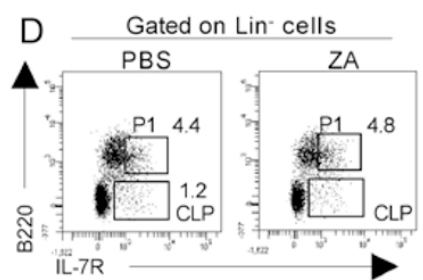

E Gated on P1 (B220+ IL7-R+)
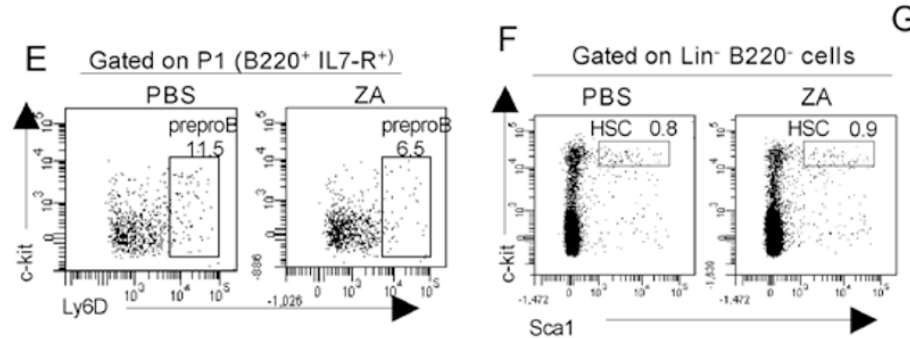

G

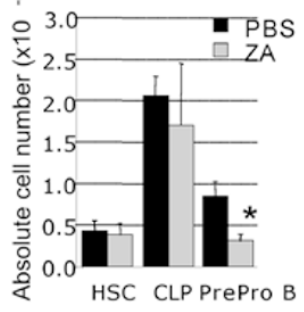

Figure 3 In vivo effect of ZA on B-cell sub-populations in the bone marrow. (A) Flow cytometric analysis of B220 $0^{+} \mathrm{CD} 19^{+}$total B cells, CD11 $\mathrm{b}^{+} \mathrm{Gr} 1^{+}$myeloid in the bone marrow of PBS- and ZA-treated mice. (B) B cell subsets were analyzed by flow cytometry in the bone marrow. They were defined as follows: pro-B cells $=\mathrm{B} 220^{+} \mathrm{CD} 43^{+}$; pro-B plus pre- $\mathrm{B}$ cells $=\mathrm{B}^{2} 20^{\text {low }} \mathrm{IgM}^{-}$; pre-B cells

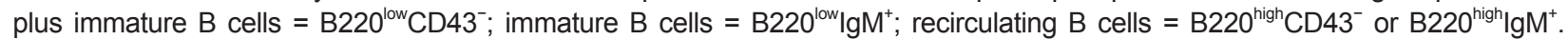
Panels $\mathbf{A}$ and $\mathbf{B}$ are representative of results obtained for at least six mice in four independent experiments. (C) The absolute cell number of B-cell subsets was calculated from the flow cytometric analysis and is presented as the mean \pm SD of six to nine mice per group $\left({ }^{\star} P<0.01\right)$. (D) Common lymphoid progenitors (CLPs) were defined as Lin- $\left(\mathrm{CD}^{-} \mathrm{CD}^{-} 1 \mathrm{~b}^{-} \mathrm{Gr}^{-}{ }^{-} \mathrm{TER}^{-} \mathrm{C}^{-} \mathrm{CD} 11 \mathrm{c}^{-} \mathrm{CD} 49 \mathrm{~b}^{-}\right.$

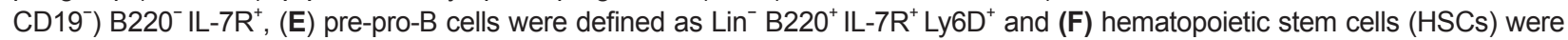
defined as $\mathrm{Lin}^{-} \mathrm{B} 220^{-} \mathrm{Sca}-1^{+} \mathrm{C}-\mathrm{Kit}^{+}$. Results are representative of five mice. (G) The absolute cell number of HSCs, CLPs and preproB cells was calculated from the flow cytometric analysis and is presented as the mean \pm SD of 5 mice per group ( ${ }^{*} P<0.01$ ).

pre-B plus immature B cells, as well as B-cell apoptosis and proliferation was not affected by ZA at any dose from $10^{-8} \mathrm{M}$ to $10^{-6} \mathrm{M}$ (Figure $4 \mathrm{C}$ and data not shown). Moreover, endogenous IL-7 expression by ST2 cells was equivalent in control and ZA-treated cells, at any ZA concentration (data not shown).

Altogether, our results demonstrated that the impaired B-cell development observed in the bone marrow of osteopetrotic mice is not the consequence of a direct effect of ZA on B cells. Rather, it is likely due to microenvironmental changes resulting from a reduced osteoclastic activity. One possible consequence explaining the decreased B-cell number could be an impaired retention and a mobilization of B-cell precursors outside of the bone marrow.

\section{ZA indirectly affects bone marrow stromal cells}

Retention of B cells in their niche is highly dependent on cell interactions between B-cell progenitors and stromal cells expressing CXCL12 or IL-7 [5]. Thus, we analyzed the expression of these genes in the bone marrow of PBS- and ZA-treated mice by real time RT-PCR. Expression of both genes was dramatically decreased in ZA-treated mice compared with controls (Figure 5A). In contrast, no significant change was observed in the expression of macrophage colony-stimulating growth factor (M-CSF), important for myeloid cell differentiation and also produced by stromal cells (Figure 5A). To confirm that these variations affect stromal cells, we sorted $\mathrm{CD} 45^{-}$cells representing stromal cells from the bone marrow of PBS- and ZA-treated mice. We observed a 10-fold reduction in the expression of CXCL12 or IL-7 and no change in M-CSF expression in the bone marrow stromal cells of ZA-treated mice compared with controls (Figure 5B).

To further understand the effect of ZA on stromal cells, we treated in vitro $\mathrm{CD} 45^{-}$stromal cells from normal mice with 0 to $10^{-6} \mathrm{M}$ ZA for $24 \mathrm{~h}$ (not shown) and $48 \mathrm{~h}$ (Figure 5C and 5D). ZA did not affect stromal cell viability (not shown) and had no effect on the expres- 
sion of CXCL12 or IL-7, at whatever concentration used and even in the presence of OCLs from control or osteopetrotic oc/oc mice (Figure 5C and 5D). Thus, the results observed in vivo on the production of CXCL12 and IL-7 by stromal cells were probably not due to a direct effect of ZA on stromal cells, nor to regulation of stromal gene expression cell by factors produced by OCLs.

However, stromal cells and OCLs are known to interact and regulate each others [34, 35]. Therefore, we wondered whether reduction of OCL activity could affect stromal populations and we analyzed mesenchymal and osteoblast progenitors by performing colony forming unit-fibroblast (CFU-F) and colony forming unit-alkaline phosphatase (CFU-ALP) assays, respectively, on total bone marrow cells from PBS- and ZA-treated mice. The number of CFU-F increased twice, but we observed a twofold decrease in CFU-ALP in ZA-treated mice compared with control mice (Figure 6A). In vivo histological analysis of the femora after staining of ALP activity revealed a twofold reduction in $\mathrm{ALP}^{+}$cells in the trabecular zones of ZA-treated mice compared with controls (Figure 6B). Lastly, real-time RT-PCR analysis showed that expression of Runx2, a key regulator of osteoblast differentiation [36], as well as expression of the osteoblastic markers osteocalcin, bone sialoprotein $(B S P)$ and collagen-1 $\alpha 1$, was lower in $\mathrm{CD} 45^{-}$cells from ZA-treated mice than from PBS-treated mice (Figure 6C). Altogether, these results indicated a modification in mesenchymal cell populations with a reduced engagement in the osteoblastic pathway in ZA-treated mice compared with
A

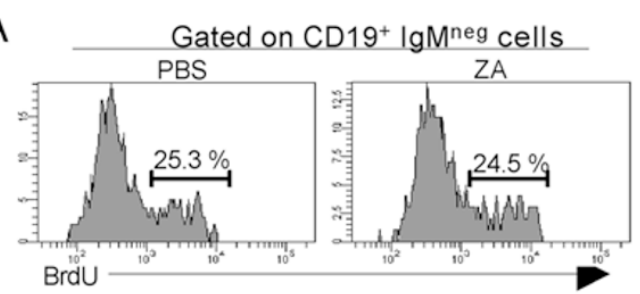

B

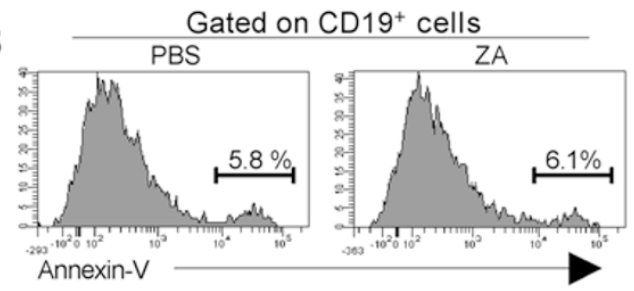

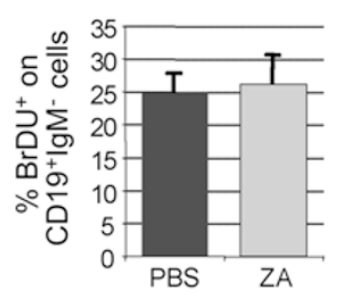

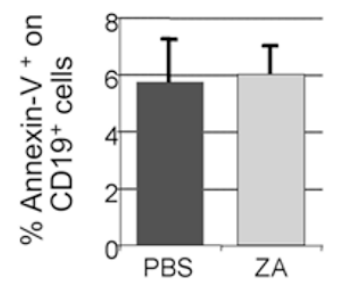

C
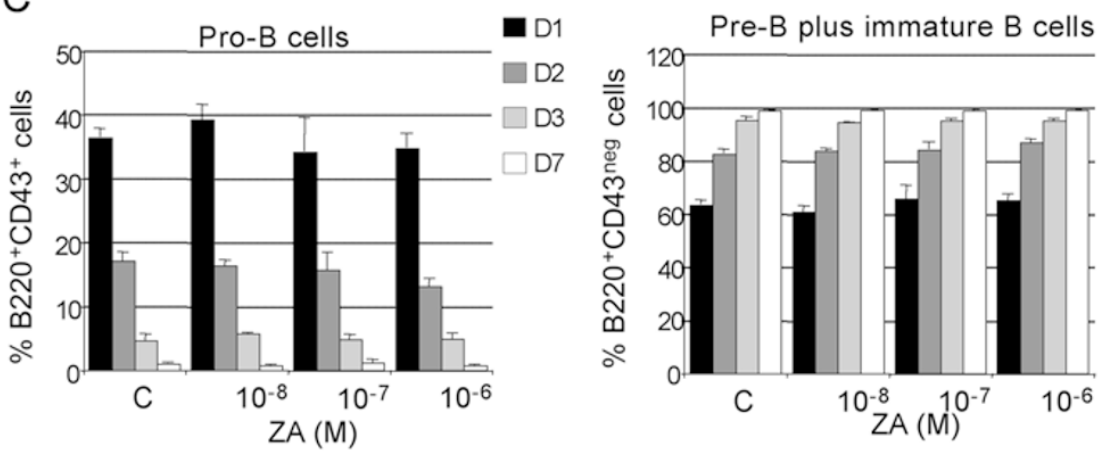

Figure 4 Effect of ZA on B-cell proliferation, apoptosis and differentiation. (A) B-cell proliferation was analyzed by flow cytometry in the bone marrow, after in vivo BrdU incorporation to the DNA and labeling with anti-BrdU, anti-CD19 and anti-IgM antibodies. The percentage of $\mathrm{CD}_{1}{ }^{+} \mathrm{IgM}^{-} \mathrm{BrdU}^{+}$cells is indicated. Histograms present the mean \pm SD of at least six mice per group. (B) Apoptosis was evaluated by flow cytometry on B cells from the bone marrow by staining with an anti-CD19 antibody and annexin- $\mathrm{V}$. The percentage of $\mathrm{CD} 19^{+}$annexin- $\mathrm{V}^{+}$cells is indicated. Histograms present the mean $\pm \mathrm{SD}$ of at least six mice per group. (C) $\mathrm{CD} 19^{+} \mathrm{B} 220^{\mathrm{low}} \mathrm{IgM}^{-} \mathrm{B}$-cell progenitors from the bone marrow of normal mice were layered onto ST2 stromal cells with $10 \mathrm{ng} / \mathrm{ml} \mathrm{IL-7,} \mathrm{in} \mathrm{the} \mathrm{presence} \mathrm{of} 0$ to $10^{-6} \mathrm{M}$ ZA. Cells were cultured for 1 (D1), 2 (D2), 3 (D3) and 7 days (D7), and their differentiation was analyzed by flow cytometry using anti-B220 and -CD43 antibodies. Histograms represent the mean $\pm \mathrm{SD}$ of the percentage of $\mathrm{B} 220^{+} \mathrm{CD} 43^{+}$pro- $\mathrm{B}$ cells and $\mathrm{B} 220^{+} \mathrm{CD} 43^{-}$pre-B plus immature $\mathrm{B}$ cells, of triplicate from three independent experiments. 
controls. The same reduction in CFU-ALP and in ALP cell number was observed in oc/oc mice (Supplementary information, Figure S2), indicating that this lower osteoblastic engagement is a consequence of the reduced OCL activity rather than a direct effect of ZA on osteoblasts.

\section{$Z A$ affects $B$-cell homing in the bone marrow}

Bone marrow failure is often compensated in other hematopoietic organs, in particular in the spleen. Our results showed that the percentage and absolute number of $\mathrm{B} 220^{+} \mathrm{CD} 19^{+}$total B cells were significantly increased in the spleen of ZA-treated mice compared with controls (Figure 7A and 7B). Moreover, this increase in absolute cell number affected all B-cell subsets from pro-B to mature B cells (Figure 7B). However, the percentage of $\mathrm{B}$-cell subsets remained unchanged in the blood (Figure 7C), revealing that the variations observed in the spleen are specific of this organ. Together with the failure in the bone marrow environment, these data suggest that, in the ZA-induced osteopetrotic model, B-cell homing in the bone marrow might be impaired.

To assess this point, we have followed the location of B-cell progenitors in PBS- and ZA-treated mice. Pro-B plus pre-B precursor cells from actin-GFP mice were transferred into PBS- and ZA-treated mice by intravenous injection in the caudal vein. After $24 \mathrm{~h}$, in PBStreated mice, the majority of cells migrate into the bone marrow compared with the spleen (Figure 7D and 7E).
A

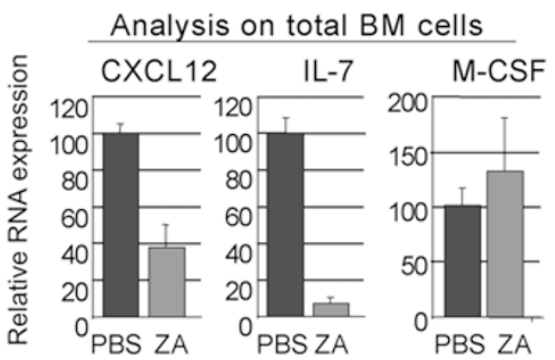

B

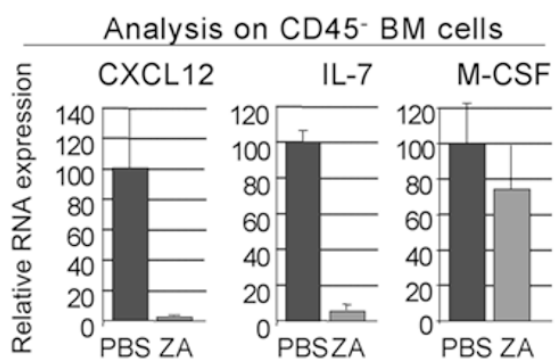

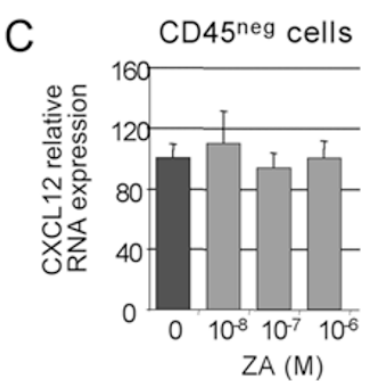

$\mathrm{D}$

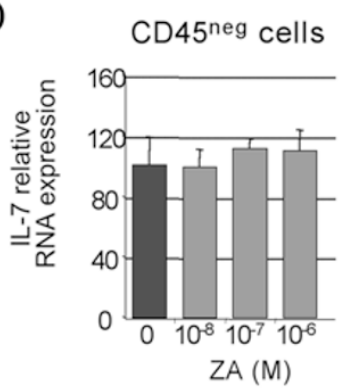

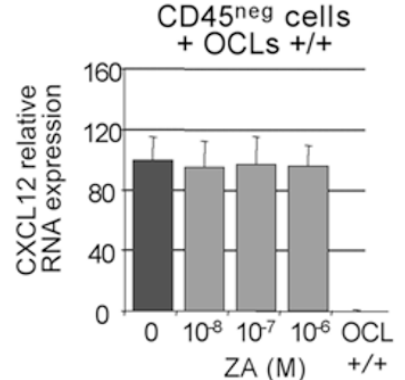

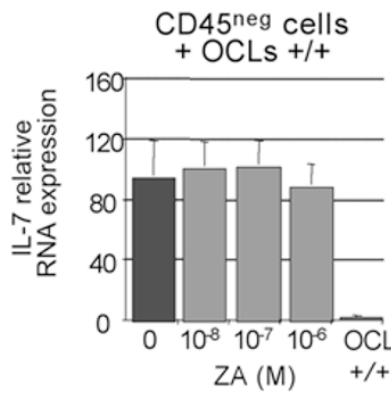

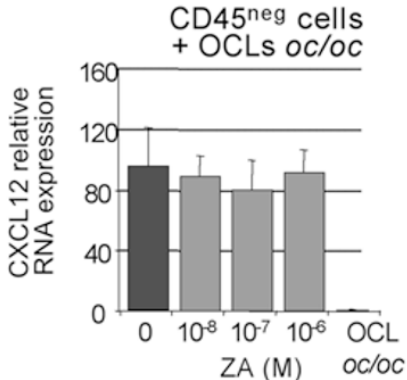

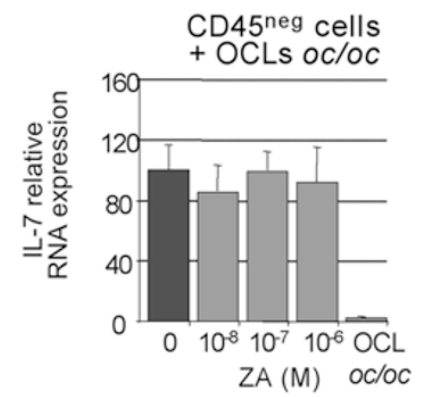

Figure 5 Effect of ZA on the expression of SDF-1 and IL-7 by stromal cells. (A) Real-time RT-PCR analysis on RNA from the bone marrow of PBS- and ZA-treated mice. Results are presented as the mean \pm SD of triplicates from three experiments with at least five mice in each group. (B) Real-time RT-PCR analysis on RNA from CD45 bone marrow stromal cells freshly isolated from PBS- and ZA-treated mice. (C-D) Real-time RT-PCR analysis on RNA from CD45- bone marrow cells from normal mice treated in vitro with 0 to $10^{-6} \mathrm{M}$ ZA for $48 \mathrm{~h}$. CD45 cells were cultured alone or were cocultured with OCLs from $+/+$ or oc/oc mice. Results are presented as the mean \pm SD of triplicates from three independent experiments. In all experiments, $C t$ values were normalized to the 36B4 RNA. Differences were calculated with the $2^{-\triangle C t}$ method and expressed as percentage relative to the values obtained for control cells (without $Z A$ ). 
A
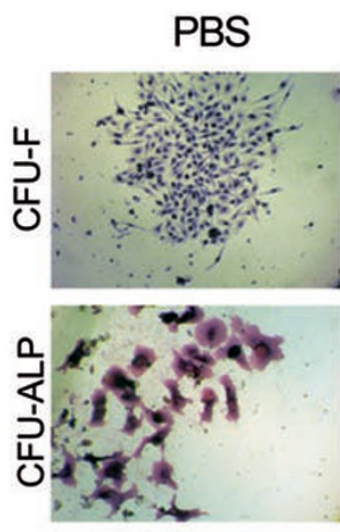

B

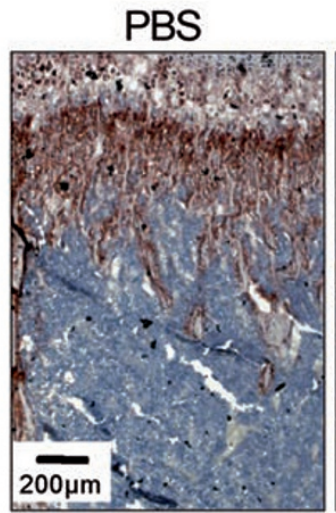

ZA
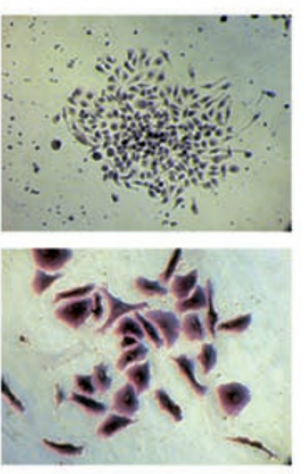

ZA

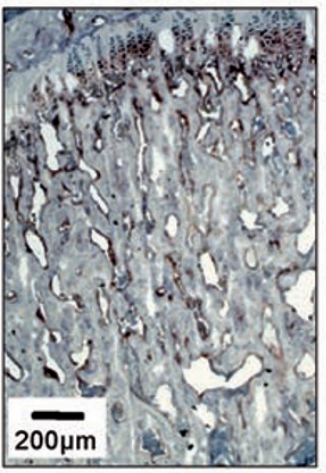

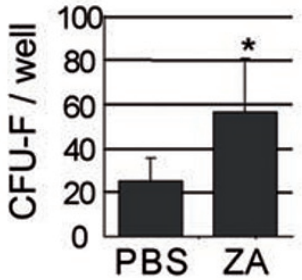
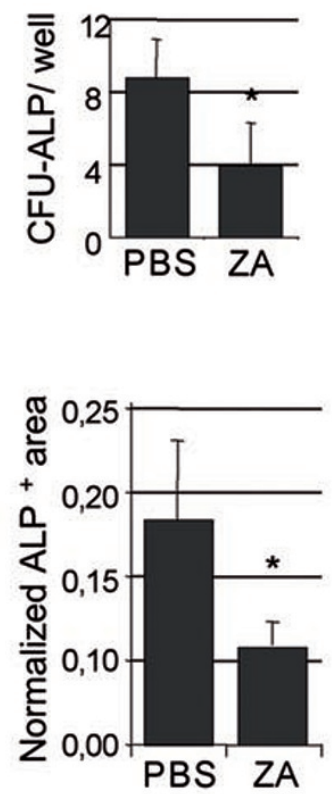

C
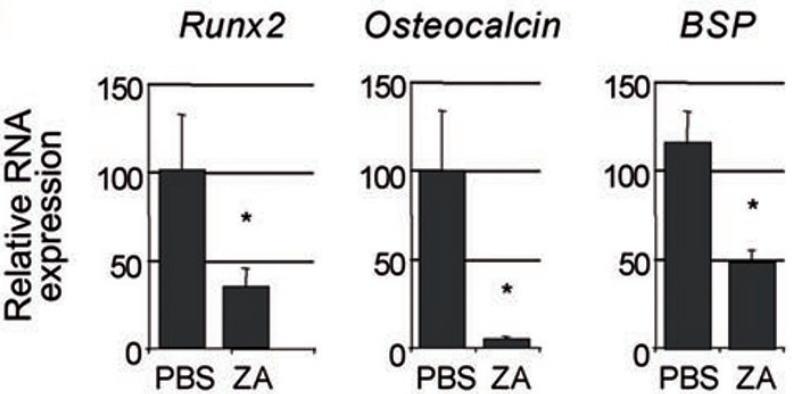

Col1 $\alpha 1$

Figure 6 Reduced osteoblastic engagement in ZA-treated mice. (A) CFU-F and CFU-ALP assays from total bone marrow cells of PBS-and ZA-treated mice Results are representative of the mean $\pm \mathrm{SD}$ of triplicates from three mice in each group. $\left({ }^{*} P<\right.$ 0.01). (B) ALP staining of the femoral bone of PBS- and ZA-treated mice. ALP ${ }^{+}$areas were analyzed in the trabecular zone and were normalized to the trabecular zone areas. Data are presented as the mean \pm SD of at least six images per mice and three mice per group ( $\left.{ }^{\star} P<0.01\right)$. (C) Real-time RT-PCR analysis on RNA from CD $45^{-}$bone marrow stromal cells freshly isolated from PBS- and ZA-treated mice. Results are presented as the mean \pm SD of triplicates from three mice. Ct values were normalized to the 36B4 RNA. Differences were calculated with the $2^{-\Delta C t}$ method and expressed as percentage relative to the values obtained for PBS-treated mice $\left({ }^{\star} P<0.01\right)$.

In ZA-treated mice, B-cell progenitors are able to reach the bone marrow, but the number of B-cell progenitors retained in this organ is significantly lower than in PBStreated mice (Figure 7D and 7E). On the contrary, the number of injected cells located in the spleen is signifi- cantly increased compared with controls (Figure 7D and 7E). These data revealed that inhibition of OCL activity result in a defect in the location of B-cell precursors in the bone marrow leading to an increased retention into the spleen. 

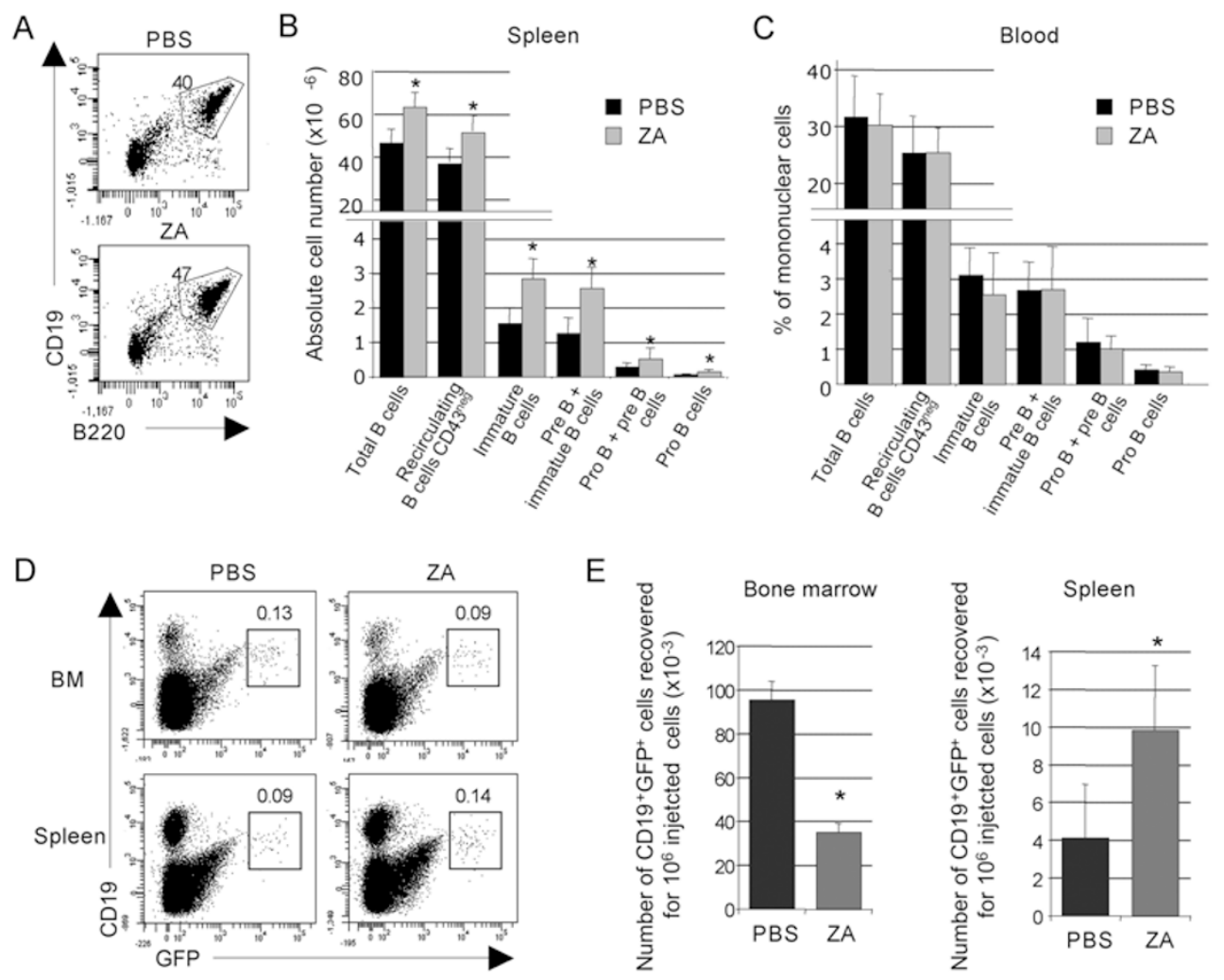

Figure 7 Effect of ZA on the homing of B-cell progenitors in vivo. (A) Flow cytometric analysis of total B220 ${ }^{+} \mathrm{CD} 19^{+} \mathrm{B}$ cells in the spleen of PBS- and ZA-treated mice. (B) Absolute cell number of subset defined as described in Figure 3B was calculated. Results are presented as the mean \pm SD of seven to nine mice per group $\left({ }^{\star} P<0.05\right)$. (C) B-cell subsets were also analyzed in the blood and results are presented as the mean percentage \pm SD for five mice per group. (D) $\mathrm{CD}^{+} 9^{+} \mathrm{B} 220^{\mathrm{low}} \mathrm{IgM} \mathrm{I}^{-}$ B-cell progenitors from actin-GFP mice were injected into PBS- and ZA-treated mice. The distribution of GFP ${ }^{+}$CD19 ${ }^{+}$cells was analyzed by flow cytometry after $24 \mathrm{~h}$, in the bone marrow (BM) and the spleen. Percentages of the GFP ${ }^{+} \mathrm{CD} 19^{+}$cells are indicated. (E) The absolute number of GFP ${ }^{+} \mathrm{CD} 19^{+}$cells in the bone marrow and spleen of PBS- and ZA-treated mice was calculated from the flow cytometric analysis. Data are presented as the mean \pm SD of GFP ${ }^{+}$CD $19^{+}$recovered cells per $10^{6}$ injected cells ( $n=4$ to 6 per group) and are representative of two independent experiments $\left({ }^{*} P<0.01\right)$.

\section{Discussion}

Alteration of B-cell development is a characteristic of many genetically induced osteopetrotic models [14-19]. This link between osteopetrosis and B lymphocytopenia has been attributed either to mutations in genes important for both OCL differentiation and B-cell development, or to the consequences of osteopetrosis on bone microenvironment. In osteopetrotic oc/oc mice, B lymphopoiesis is blocked at the pro-B to pre-B-cell transition [20]. This block is likely because of a microenvironmental defect rather than to a cell autonomous defect of the B-cell lineage, because B-cell progenitors from oc/oc mice are able to differentiate in vitro into immature B cells and also because IL-7 injection in these mice partially restored B lymphopoiesis [22, 23]. In this study, we have shown that restoration of OCL activity by transfer of
cDCs from $+/+$ mice is associated with a rescue of $B$ lymphopoiesis (Figure 1). As no B-cell precursors were transferred in our approach, our results clearly demonstrate the existence of a link between OCL activity and B lymphopoiesis. However, oc/oc mice have a too short life span and too low bone marrow cellularity to allow many further experiments to address the mechanisms involved in this process.

Therefore, we have used an osteopetrotic-like model induced by ZA, a potent bisphosphonate. Changes in the bone phenotype of ZA-treated mice affect the trabecular zone of long bones leading to an increased trabecular bone density (Figure 2). The affected zones increase in size with time (not shown), to reach around one-third of the bone marrow at 6 weeks of treatment. These areas correspond to regions where bone-remodeling activity is the most important. Indeed, regions of intense bone 
mineralization and bone resorption correspond to those where bisphosphonates are incorporated and become exposed to OCLs [24], probably explaining why these zones are more affected than others by ZA treatment.

$\mathrm{ZA}$ is an inhibitor of the farnesyl pyrophosphate synthase, an enzyme in the mevalonate pathway that is necessary for lipid modification of small GTP-binding proteins $[37,38]$. Interference with the activity of these proteins alters cytoskeleton organization and intracellular trafficking in OCLs, resulting in inhibition of their function $[39,40]$. In our study, the increased BV/TV of trabecular bone is not linked with a defect in myeloid cell number or OCL differentiation capacity, but rather to an impaired attachment of OCLs to the bone matrix. In arthritic rats treated with high doses of ZA, it was reported that the number of OCLs was increased, probably due to a feedback mechanism responding to reduced OCL activity [41]. In human tumor necrosis factor transgenic mice that develop arthritis, administration of ZA according to the same protocol we used, decreased the number of synovial OCLs but did not affect the number of trabecular OCLs [26]. Furthermore, it was reported that alendronate, another bisphosphonate, also inhibits the attachment of OCLs on the bone matrix [42]. All these observations suggest that, in trabecular bone remodeling, the primary mechanism of ZA action is an inhibition of OCL function rather than an induction of their apoptosis. Histomorphometric and histological analysis revealed that osteopetrosis induced by ZA treatment is mild and less severe than in $o c / o c$ mice. This difference is likely because of the complete absence of OCL activity starting at the embryonic stage in $o c / o c$ mice resulting in an impaired bone formation [29, 43], whereas in the ZA model, OCL activity is blocked in young adult mice displaying a normal bone.

In response to ZA treatment, the number of B cells is decreased by $50 \%$ in the bone marrow. This decrease affects all B-cell subsets from the pre-pro-B stage and is restricted to the bone marrow. Moreover, we have shown that ZA does not directly affect B-cell differentiation, proliferation or apoptosis (Figure 4). All these observations demonstrate that reduction of B-cell number in affected bone marrow is not due to a direct effect of ZA on $\mathrm{B}$ cells, but rather to modifications in the bone microenvironment due to reduced OCL activity. No accumulation of pro-B cells was detected in the ZA-induced osteopetrotic model, in contrast with the oc/oc model [20]. This difference in B-cell phenotype is probably linked to the difference in the severity of osteopetrosis and the age of apparition of the osteopetrotic phenotype.

Contact-mediated signals from stromal cells and soluble factors are required for the development of B-cell precursors. Among them, CXCL $12^{+}$stromal cells and IL- $7^{+}$stromal cells play a pivotal role in B-cell differentiation $[10,12,13]$. IL-7 is the major growth factor for developing B cells: signals from the IL-7R are required during the pro-B-cell stage for further differentiation, and deficiencies in either IL-7 or IL-7R result in severe defects in B-cell development $[13,44]$. In mice lacking CXCL12, the number of B-cell progenitors is severely reduced in the bone marrow [10]. Moreover, animals reconstituted with cells deficient for CXCR4, the receptor for CXCL12, display a reduced number of donor-derived pro-B, pre-B and immature B cells in bone marrow [45], whereas this number is increased in the periphery, suggesting that CXCR4 and CXCL12 play a role in the retention of B-cell precursors in bone marrow [11]. CX$\mathrm{CL}_{12}{ }^{+}$stromal cells and $\mathrm{IL}-7^{+}$stromal cells provide successive niche, in which $\mathrm{B}$ cells progress during their differentiation [5]. Thus, the dramatic reduction in IL-7 and CXCL12 expression observed in CD45 stromal cells from bone marrow of ZA-treated mice reveals an alteration in these niches, and is probably a major cause of the impaired B-cell development and retention observed in this organ.

Changes in IL-7 and CXCL12 expression by bone marrow stromal cells might be either due to impaired interactions with inactive OCLs or to a modification in cells producing these factors. Our in vitro data showed that the presence of active $(+/+)$ or inactive $(o c / o c)$ OCLs did not modulate the expression of IL-7 and CXCL12 in the presence of ZA (Figure 5), and thus are not in favor of the first hypothesis. Due to the dramatic alterations of the bone structure, it was not possible to perform immunohistochemistry on IL-7 and CXCL12 in ZA-treated mice. However, the low number of $\mathrm{ALP}^{+}$cells, the weak expression of osteoblastic markers and the reduced CFUALP number observed in the bone marrow of these mice reveal a modification in the osteoblastic engagement in osteopetrotic mice, that could explain the changes in IL-7 and CXCL12 expression. Indeed, osteoblastic cells produce these factors and are important component of the B-cell niches. In vivo ablation of osteoblasts alters B-cell differentiation despite that HSCs were still present in the bone marrow [2-4]. These data are consistent with the absence of effect we observed on HSCs after ZAtreatment.

Direct effects of ZA on osteoblast differentiation and function are not clear, as some studies report a stimulatory effect, whereas others report an inhibitory effect [46-49]. This discrepancy is probably because of the differences in the doses, protocols and species used. However, stromal cells and osteoblasts are not able to take up bisphosphonates [50], and we did not observe any 
direct effect of ZA on stromal cell expression of IL-7 and CXCL12, as assessed by our in vitro analysis. Moreover, we observed a similar in vivo decrease in osteoblastic engagement and $\mathrm{ALP}^{+}$cells in osteopetrotic oc/oc mice (Supplementary information, Figure S2). Therefore, it is very likely that most of the alterations observed in osteoblasts are due to alterations of the bone remodeling cycle resulting from the reduction of bone resorption. Indeed, it is well established that secreted or membrane-bound molecules produced by OCLs, and cytokines and growth factors released from the bone matrix by resorbing OCLs stimulate osteoblast precursors $[34,35]$. Therefore, such factors are likely to modulate osteoblast differentiation and function and, as suggested by our results, they might control the fate of stromal cells involved in the B-cell niches.

In conclusion, our study demonstrates that block in OCL activity is associated with B lymphocytopenia in the bone marrow. The reduction of B-cell number is due to an impaired retention of B-cell progenitors in the bone marrow, associated with modifications in the expression pattern of cytokines and growth factors by bone marrow stromal cells. Our results suggest that these modifications are a consequence of reduced osteoblastic engagement of stromal cells probably linked to an impaired communication with OCLs due to the absence of bone resorption. These data clearly demonstrate that OCL activity can modulate B-cell development in the bone marrow and provide novel basis for the regulation of the B-cell niches.

\section{Materials and Methods}

\section{Animals and treatments}

Five-week-old female Balb/C mice (Janvier, France) were maintained in our central animal facility in accordance with the general guidelines of the "Direction des Services Vétérinaires". They received a daily intraperitoneal (IP) injection of $2 \mu \mathrm{g} \mathrm{ZA}$ (Novartis) in $100 \mu \mathrm{PBS}$ without calcium and magnesium or 100 $\mu 1$ PBS alone (control mice), 5 days a week for 6 weeks. Animals were killed by cervical dislocation.

oc/oc mice were genotyped, as described [20], at 1 day after birth. They received a total body irradiation of 3 Gy 1 day after birth. On day 2 after birth, they received an IP injection of either $50 \mu \mathrm{PBS}$ (control oc/oc mice) or $5 \times 10^{6}$ splenic DCs purified from naive $+/+$ mice in $50 \mu \mathrm{l}$ PBS. Animals were killed at the age of 7 weeks.

\section{Purification of conventional splenic DCs}

cDCs were sorted from spleens of 5-week-old naive $+/+$ mice as described previously [29]. Briefly, CD $11 \mathrm{c}^{+}$splenocytes were enriched by magnetic separation on microbeads (Miltenyi-Biotech), after depletion of T, B, NK cells, monocytes and granulocytes, by treatment with monoclonal antibody mixture containing anti-CD3 (17A2), anti-CD19 (1D3), anti-CD49b (DX5), and anti-Gr1 (RB6-
8C5; Pharmingen) and separation with anti-rat Ig-coated magnetic beads (Dynal). Enriched cells were labeled with APC-CD11c (HL3) and FITC-IAb (AF6-120.1), and the CD11 $\mathrm{c}^{+} \mathrm{IAb}^{+}$DCs were sorted on a FACS Aria cell sorter (Becton-Dickinson) with high purity sorting $(100 \%)$.

\section{Cell preparation and flow cytometry analysis}

Bone marrow cells were obtained by crushing the femora into small pieces and vigorous pipetting as previously described [20]. Splenocytes were isolated by filtration through a $40 \mu \mathrm{m}$ cell strainer (Becton Dickinson). Blood cells were obtained by intracardiac puncture. After red blood cell lysis, cells were analyzed by flow cytometry using the following conjugated antibodies: B220 (RA3-6B2), CD43 (S7), CD19 (1D3), IgM (R6-60.2), CD11b (M1/70), Gr1 (RB6-8C5), TER119, CD3 (17A2), CD11c (HL3), CD49b (Dx5), IL-7R (A7R34), Ly6D (49H4), c-kit (2B8), Sca1 (D7) (Pharmingen) as previously described [20]. After washes, the labeled cells were analyzed on a FACS Canto (Becton Dickinson).

\section{High resolution $\mu C t$ and radiography}

Fixed femora were scanned with high resolution $\mu \mathrm{Ct}$ (Viva CT40, Scanco) in the PLEXAN facility (Medical Faculty, Jean Monnet University, Saint-Etienne, France) following procedures described in [51]. Data were acquired at $55 \mathrm{keV}$ with a resolution of $10 \mu \mathrm{m}$ cubic. Three-dimensional reconstructions were generated for visual representation. Radiographic analysis was performed on an X-ray system (Faxitron MX-20) for $15 \mathrm{~s}$ at $19 \mathrm{kV}$.

\section{Immunohistochemistry}

TRACP and ALP staining, femora were fixed in 4\% paraformaldehyde for $24 \mathrm{~h}$ at $4{ }^{\circ} \mathrm{C}$, decalcified in $10 \%$ EDTA for 10 days at $4{ }^{\circ} \mathrm{C}$ and incubated overnight in a $30 \%$ sucrose solution and $8 \mu \mathrm{m}$ sections were obtained with a cryotome (ThermoShandon). Bone sections were stained for TRACP activity with the leukocyte acid phosphatase kit (Sigma) and for ALP activity with the leukocyte alkaline phosphatase kit, (Sigma) and were observed by light microscopy (CarlZeiss). ALP staining was analyzed in the trabecular zone of the femora: images were analyzed with the Image $\mathrm{J}$ software (Wayne Rasband, NIH Image System) to define the areas corresponding to ALP staining. These areas were normalized to the areas of the trabecular zone. For Von Kossa staining, undecalcified bones were fixed in $4 \%$ paraformaldehyde, dehydrated and embedded in methylmethacrylate. Sections $(7 \mu \mathrm{m})$ were stained with the Von Kossa procedure.

\section{OCL differentiation and resorption activity}

Bone marrow cells from PBS- or ZA-treated mice were seeded at $10^{5}$ cells $/ \mathrm{cm}^{2}$ in MEM $\alpha$ medium containing $5 \%$ fetal calf serum (Hyclone, Perbio) and with 50ng/ml RANK-L and $25 \mathrm{ng} / \mathrm{ml}$ M-CSF. After 1 week, TRACP activity was revealed with the leukocyte acid phosphatase kit (Sigma) and multinucleated TRACP ${ }^{+}$ cells were enumerated under a light microscope (Axiovert, Zeiss). For resorption assays, cells were seeded onto dentin slices, in the same conditions. After 1 week, cells were removed by sonication and resorption lacunae were stained with toluidin blue.

\section{B-cell apoptosis and proliferation}

B-cell apoptosis was detected by flow cytometry after staining with antibodies reactive to CD19 and annexin-V-FITC according 
to the manufacturer protocol (Becton Dickinson). B-cell proliferation was evaluated by BrdU incorporation: 1 day before killing, animals received an IP injection of $1 \mathrm{mg}$ BrdU solution (Becton Dickinson). Cells were labeled with antibodies reactive to CD19 and IgM, fixed, permeabilized and treated with DNase according to the manufacturer instructions (Becton Dickinson). They were labeled with an anti BrdU antibody and analyzed by flow cytometry on a FACS Canto (Becton Dickinson).

\section{In vitro $B$-cell analysis}

Bone marrow cells were isolated from normal mice and labeled with antibodies reactive to B220, CD19 and IgM. $\mathrm{CD} 19^{+} \mathrm{B} 220^{\text {low }} \mathrm{IgM}^{-}$cells representing pro-B plus pre-B cells were purified on a cell sorter (FACS Aria, Becton Dickinson). They were seeded at $2 \times 10^{5}$ cells/well over confluent ST2 cells irradiated at a dose of $30 \mathrm{~Gy}$, in the presence of $10 \mathrm{ng} / \mathrm{ml} \mathrm{IL-7} \mathrm{and}$ without or with ZA $\left(10^{-8}\right.$ to $\left.10^{-6} \mathrm{M}\right)$. At the indicated time, cells were collected, labeled with B220 and CD43 antibodies, and then analyzed by flow cytometry on a FACS Canto (Becton Dickinson).

\section{CD45 stromal cell preparation and culture}

After red cell lysis, bone marrow cells were labeled with an anti-CD45 antibody and the CD45 population, containing mainly stromal cells, was purified on a cell sorter (FACS Aria, Becton Dickinson) for PCR analysis. This $\mathrm{CD} 45^{-}$population also served for in vitro analysis: cells were seeded at $3 \times 10^{4}$ cells in a 24-well plate in MEM medium containing 5\% fetal calf serum (Hyclone, Perbio) and they were treated with the indicated concentration of ZA for 24 and $48 \mathrm{~h}$. For coculture with OCLs, bone marrow cells from $+/+$ or $o c / o c$ mice were seeded at $10^{5}$ cells $/ \mathrm{cm}^{2}$ in MEM $\alpha$ medium containing 5\% fetal calf serum (Hyclone, Perbio) and with $50 \mathrm{ng} / \mathrm{ml}$ RANK-L and $25 \mathrm{ng} / \mathrm{ml}$ M-CSF. After 1 week, cells were harvested by trypsin/EDTA and OCLs were sorted on a cell sorter (FACS Aria) based on their size. OCLs were seeded at $5 \times$ $10^{3}$ cells $/ \mathrm{cm}^{2}$ together with $3 \times 10^{4} \mathrm{CD} 45^{-}$cells sorted from normal mice. These cocultures were performed without or with the indicated concentration of ZA for $48 \mathrm{~h}$.

\section{Real-time PCR analysis on stromal cells}

Total RNA from stromal cells was extracted by adsorption onto silica membranes (Macherey-Nagel). RNA (1 $\mu \mathrm{g})$ was reverse transcribed with random primers according to the manufacturer protocol (Invitrogen). Real-time PCR analysis was performed on an ABI Prism 7700 (Applied Biosystems) as previously described [20], in triplicate. Cycle threshold $(C \mathrm{t})$ values were determined and results were normalized to the acidic ribosomal phosphoprotein P0 (36B4) RNA on the same plate. Differences in gene expression were calculated using the $2^{-\Delta C t}$ method [52]. Generating a melting curve of the PCR product and analysis by gel electrophoresis controlled specificity of amplification. The primers used were: $36 B 4 ; 5^{\prime}$-TCCAGGCTTTGGGCATCA-3' and 5'-CTTTATCAGCTGCACATCACTCAGA-3'; Il-7: 5'-GGCACACAAACACTGGTGAACT-3' and 5'-TGCATCATTCTTTTTCTGTTCCTT-3'; Cxcl12: 5'-GAGCCAACGTCAAGCATCTG-3' and 5'-CGGGTCAATGCACACTTGT-3'; M-csf: 5'-TTAAAGACAACACCCCCAATGC-3' and 5'-TCAGGTTATTGGAGAGTTCCTGGA-3'; osteocalcin: 5'-CCACCCGGGAGCAGTGT-3' and 5'-CTAAATAGTGATACCGTAGATGCGTTTG-3'; Runx-2: 5'-TTTAGGGCGCATTCCTCATC-3' and 5'-TGTCCTTGTG-
GATTAAAAGGACTTG-3'; BSP: CCAAGCACAGACTTTTGAGTTAGC-3' and 5'-CTTTCTGCATCTCCAGCCTTCT-3'; Colla1: 5'-GCGAAGGCAACAGTCGCT-3' and 5'-CTTGGTGGTTTTGTATTCGATGAC-3'.

\section{CFU assays}

Bone marrow cells from PBS-treated, ZA-treated $+/+$ or $o c / o c$ mice were seeded at $5 \times 10^{5}$ cells/well in 12-well plates in MEM $\alpha$ medium containing 10\% fetal calf serum (Hyclone, Perbio) for 20 days, as described by Kuznetsov et al. [53]. After fixation with acetone/citrate, CFU-Fs were visualized by staining with hematoxylin and CFU-ALPs by staining with the leukocyte alkaline phosphatase kit (Sigma). Colonies were enumerated under a light microscope (Axiovert, Zeiss).

\section{In vivo B-cell homing}

Mice were treated with ZA or PBS for 6 weeks as described above. They received a total body irradiation of 3 Gy. At 1 day after, they received an intravenous injection of $10^{6}$ pro-B plus pre-Bcell progenitors sorted as described above from actin-GFP mice, in $100 \mu \mathrm{l} \mathrm{PBS}$, in the caudal vein. Animals were killed at $24 \mathrm{~h}$ after the injection, and the distribution of $\mathrm{GFP}^{+} \mathrm{CD} 19^{+} \mathrm{B}$ cells was analyzed by flow cytometry in the bone marrow and in the spleen.

\section{Conflict of interest}

The authors declare no competing financial interests.

\section{Acknowledgments}

We thank M Topi for animal care and technical assistance and $\mathrm{T}$ Juhel for injections in the mouse caudal vein. We also thank $\mathrm{L}$ Malaval and $\mathrm{N}$ Laroche for their help in the $\mu C t$ analysis (PLEXAN facility, Medical Faculty, Jean Monnet University, Saint-Etienne, France). We also greatly acknowledge F Prodon at the cell imaging facility of the "Centre Méditérranéen de Médecine Moléculaire, Nice, France (MICA plateform) for his help in quantification of alkaline phosphatase labeling. This work was supported by the "Ministère de l'Enseignement et de la Recherche" (AM).

\section{References}

1 Walsh MC, Kim N, Kadono Y, et al. Osteoimmunology: interplay between the immune system and bone metabolism. Annu Rev Immunol 2006; 24:33-63.

2 Zhang J, Niu C, Ye L, et al. Identification of the haematopoietic stem cell niche and control of the niche size. Nature 2003; 425:836-841.

3 Calvi LM, Adams GB, Weibrecht KW, et al. Osteoblastic cells regulate the haematopoietic stem cell niche. Nature 2003; 425:841-846.

4 Visnjic D, Kalajzic Z, Rowe DW, et al. Hematopoiesis is severely altered in mice with an induced osteoblast deficiency. Blood 2004; 103:3258-3264.

5 Tokoyoda K, Egawa T, Sugiyama T, Choi BI, Nagasawa T. Cellular niches controlling B lymphocyte behavior within bone marrow during development. Immunity 2004; 20:707718.

6 Wu JY, Purton LE, Rodda SJ, et al. Osteoblastic regulation of B lymphopoiesis is mediated by Gs $\{$ alpha $\}$-dependent sig- 
naling pathways. Proc Natl Acad Sci USA 2008; 105:1697616981.

7 Hardy RR, Carmack CE, Shinton SA, Kemp JD, Hayakawa $\mathrm{K}$. Resolution and characterization of pro-B and pre-pro-B cell stages in normal mouse bone marrow. J Exp Med 1991; 173:1213-1225.

8 Hardy RR, Hayakawa K. B cell development pathways. Annu Rev Immunol 2001; 19:595-621.

9 Zhu J, Garrett R, Jung Y, et al. Osteoblasts support B-lymphocyte commitment and differentiation from hematopoietic stem cells. Blood 2007; 109:3706-3712.

10 Nagasawa T, Hirota S, Tachibana K, et al. Defects of B-cell lymphopoiesis and bone-marrow myelopoiesis in mice lacking the CXC chemokine PBSF/SDF-1. Nature 1996; 382:635638.

11 Ma Q, Jones D, Springer TA. The chemokine receptor CXCR4 is required for the retention of B lineage and granulocytic precursors within the bone marrow microenvironment. Immunity 1999; 10:463-471.

12 Egawa T, Kawabata K, Kawamoto H, et al. The earliest stages of B cell development require a chemokine stromal cellderived factor/pre-B cell growth-stimulating factor. Immunity 2001; 15:323-334.

13 von Freeden-Jeffry U, Vieira P, Lucian LA, et al. Lymphopenia in interleukin (IL)-7 gene-deleted mice identifies IL-7 as a nonredundant cytokine. J Exp Med 1995; 181:1519-1526.

14 Dougall WC, Glaccum M, Charrier K, et al. RANK is essential for osteoclast and lymph node development. Genes Dev 1999; 13:2412-2424.

15 Franzoso G, Carlson L, Xing L, et al. Requirement for NFkappaB in osteoclast and B-cell development. Genes Dev 1997; 11:3482-3496.

16 Kong YY, Yoshida H, Sarosi I, et al. OPGL is a key regulator of osteoclastogenesis, lymphocyte development and lymphnode organogenesis. Nature 1999; 397:315-323.

17 Naito A, Azuma S, Tanaka S, et al. Severe osteopetrosis, defective interleukin-1 signalling and lymph node organogenesis in TRAF6-deficient mice. Genes Cells 1999; 4:353-362.

18 Tagaya H, Kunisada T, Yamazaki H, et al. Intramedullary and extramedullary B lymphopoiesis in osteopetrotic mice. Blood 2000; 95:3363-3370.

19 Yoshida H, Hayashi S, Kunisada T, et al. The murine mutation osteopetrosis is in the coding region of the macrophage colony stimulating factor gene. Nature 1990; 345:442-444.

20 Blin-Wakkach C, Wakkach A, Sexton PM, Rochet N, Carle GF. Hematological defects in the oc/oc mouse, a model of infantile malignant osteopetrosis. Leukemia 2004; 18:15051511.

21 Scimeca JC, Franchi A, Trojani C, et al. The gene encoding the mouse homologue of the human osteoclast-specific 116$\mathrm{kDa}$ V-ATPase subunit bears a deletion in osteosclerotic (oc/ oc) mutants. Bone 2000; 26:207-213.

22 Blin-Wakkach C, Wakkach A, Rochet N, Carle GF. Characterization of a novel bipotent hematopoietic progenitor population in normal and osteopetrotic mouse. J Bone Miner Res 2004; 7:1137-1143.

23 Blin-Wakkach C, Wakkach A, Quincey D, Carle GF. Interleukin-7 partially rescues B-lymphopoiesis in osteopetrotic oc/oc mice through the engagement of $\mathrm{B} 220(+) \mathrm{CD} 11 \mathrm{~b}(+)$ progeni- tors. Exp Hematol 2006; 34:851-859.

24 Russell RG, Watts NB, Ebetino FH, Rogers MJ. Mechanisms of action of bisphosphonates: similarities and differences and their potential influence on clinical efficacy. Osteoporos Int 2008; 19:733-759.

25 Hornby SB, Evans GP, Hornby SL, et al. Long-term zoledronic acid treatment increases bone structure and mechanical strength of long bones of ovariectomized adult rats. Calcif Tissue Int 2003; 72:519-527.

26 Herrak P, Gortz B, Hayer S, et al. Zoledronic acid protects against local and systemic bone loss in tumor necrosis factormediated arthritis. Arthritis Rheum 2004; 50:2327-2337.

27 Corso A, Ferretti E, Lunghi M, et al. Zoledronic acid downregulates adhesion molecules of bone marrow stromal cells in multiple myeloma. A possible mechanism for its antitumor effect. Cancer 2005; 104:118-125.

28 Guenther A, Gordon S, Tiemann M, et al. The bisphosphonate zoledronic acid has anti-myeloma activity in vivo by inhibition of protein prenylation. Int J Cancer 2010; 126:239-246.

29 Wakkach A, Mansour A, Dacquin R, et al. Bone marrow microenvironment controls the in vivo differentiation of murine dendritic cells into osteoclasts. Blood 2008; 112:5074-5083.

30 Frattini A, Blair HC, Sacco MG, et al. Rescue of ATPa3-deficient murine malignant osteopetrosis by hematopoietic stem cell transplantation in utero. Proc Natl Acad Sci USA 2005; 102:14629-14634.

31 Johansson M, Jansson L, Ehinger M, et al. Neonatal hematopoietic stem cell transplantation cures oc/oc mice from osteopetrosis. Exp Hematol 2006; 34:242-249.

32 Whyte MP, McAlister WH, Novack DV, et al. Bisphosphonate-induced osteopetrosis: novel bone modeling defects, metaphyseal osteopenia, and osteosclerosis fractures after drug exposure ceases. J Bone Miner Res 2008; 23:1698-1707.

33 Inlay MA, Bhattacharya D, Sahoo D, et al. Ly6d marks the earliest stage of B-cell specification and identifies the branchpoint between B-cell and T-cell development. Genes Dev 2009; 23:2376-2381.

34 Karsdal MA, Martin TJ, Bollerslev J, Christiansen C, Henriksen $\mathrm{K}$. Are nonresorbing osteoclasts sources of bone anabolic activity? J Bone Miner Res 2007; 22:487-494.

35 Matsuo K, Irie N. Osteoclast-osteoblast communication. Arch Biochem Biophys 2008; 473:201-209.

36 Ducy P, Zhang R, Geoffroy V, Ridall AL, Karsenty G. Osf2/ Cbfa1: a transcriptional activator of osteoblast differentiation. Cell 1997; 89:747-754.

37 van Beek E, Lowik C, Van der Pluijm G, Papapoulos S. The role of geranylgeranylation in bone resorption and its suppression by bisphosphonates in fetal bone explants in vitro: a clue to the mechanism of action of nitrogen-containing bisphosphonates. J Bone Miner Res 1999; 14:722-729.

38 Coxon FP, Helfrich MH, van 't Hof RJ, et al. Protein geranylgeranylation is required for osteoclast formation, function, and survival: inhibition by bisphosphonates and GGTI-298. J Bone Miner Res 2000; 15:1467-1476.

39 Rogers MJ. New insights into the molecular mechanisms of action of bisphosphonates. Curr Pharm Des 2003; 9:26432658.

40 Russell RG, Xia Z, Dunford JE, et al. Bisphosphonates: an update on mechanisms of action and how these relate to clini- 
cal efficacy. Ann N Y Acad Sci 2007; 1117:209-257.

41 Sims NA, Green JR, Glatt M, et al. Targeting osteoclasts with zoledronic acid prevents bone destruction in collagen-induced arthritis. Arthritis Rheum 2004; 50:2338-2346.

42 Colucci S, Minielli V, Zambonin G, et al. Alendronate reduces adhesion of human osteoclast-like cells to bone and bone protein-coated surfaces. Calcif Tissue Int 1998; 63:230-235.

43 Seifert MF, Marks SC, Jr. Morphological evidence of reduced bone resorption in the osteosclerotic (oc) mouse. Am J Anat 1985; 172:141-153.

44 Peschon JJ, Morrissey PJ, Grabstein KH, et al. Early lymphocyte expansion is severely impaired in interleukin 7 receptordeficient mice. J Exp Med 1994; 180:1955-1960.

45 Kawabata K, Ujikawa M, Egawa T, et al. A cell-autonomous requirement for CXCR4 in long-term lymphoid and myeloid reconstitution. Proc Natl Acad Sci USA 1999; 96:5663-5667.

46 Tauchmanova L, Ricci P, Serio B, et al. Short-term zoledronic acid treatment increases bone mineral density and marrow clonogenic fibroblast progenitors after allogeneic stem cell transplantation. J Clin Endocrinol Metab 2005; 90:627-634.

47 von Knoch F, Jaquiery C, Kowalsky M, et al. Effects of bisphosphonates on proliferation and osteoblast differentiation of human bone marrow stromal cells. Biomaterials 2005; 26:6941-6949.

48 Recker RR, Delmas PD, Halse J, et al. Effects of intravenous zoledronic acid once yearly on bone remodeling and bone structure. J Bone Miner Res 2008; 23:6-16.

49 Orriss IR, Key ML, Colston KW, Arnett TR. Inhibition of osteoblast function in vitro by aminobisphosphonates. J Cell Biochem 2009; 106:109-118.

50 Schindeler A, Little DG. Osteoclasts but not osteoblasts are affected by a calcified surface treated with zoledronic acid in vitro. Biochem Biophys Res Commun 2005; 338:710-716.

51 Malaval L, Wade-Guéye NM, Boudiffa M, et al. Bone sialoprotein plays a functional role in bone formation and osteoclastogenesis. J Exp Med 2008; 205:1145-1153.

52 Livak KJ, Schmittgen TD. Analysis of relative gene expression data using real-time quantitative PCR and the 2(-delta delta C(T)) method. Methods 2001; 25:402-408.

53 Kuznetsov SA, Krebsbach PH, Satomura K, et al. Singlecolony derived strains of human marrow stromal fibroblasts form bone after transplantation in vivo. J Bone Miner Res 1997; 12:1335-1347.

(Supplementary information is linked to the online version of the paper on the Cell Research website.) 